\title{
Focal Adhesion Kinases in Adhesion Structures and Disease
}

\author{
Pierre P. Eleniste and Angela Bruzzaniti \\ Department of Oral Biology, Indiana University School of Dentistry, DS241, 1121 W. Michigan Street, Indianapolis, IN 46202, USA
}

Correspondence should be addressed to Angela Bruzzaniti, abruzzan@iupui.edu

Received 23 March 2012; Revised 25 May 2012; Accepted 31 May 2012

Academic Editor: Donna Webb

Copyright () 2012 P. P. Eleniste and A. Bruzzaniti. This is an open access article distributed under the Creative Commons Attribution License, which permits unrestricted use, distribution, and reproduction in any medium, provided the original work is properly cited.

Cell adhesion to the extracellular matrix (ECM) is essential for cell migration, proliferation, and embryonic development. Cells can contact the ECM through a wide range of matrix contact structures such as focal adhesions, podosomes, and invadopodia. Although they are different in structural design and basic function, they share common remodeling proteins such as integrins, talin, paxillin, and the tyrosine kinases FAK, Pyk2, and Src. In this paper, we compare and contrast the basic organization and role of focal adhesions, podosomes, and invadopodia in different cells. In addition, we discuss the role of the tyrosine kinases, FAK, Pyk2, and Src, which are critical for the function of the different adhesion structures. Finally, we discuss the essential role of these tyrosine kinases from the perspective of human diseases.

\section{Introduction}

The extracellular matrix (ECM) is an insoluble suprastructure comprised of a variety of matrix components including fibronectin, glycosaminoglycans, chrondronectin, osteonectin, collagens, laminin, proteoglycans, and growth factors [1-6]. The ECM provides the scaffold for cell attachment which is necessary for several diverse cellular activities, including cytoskeletal remodeling, polarization, differentiation, migration, and invasion [7-9]. Binding to the ECM is regulated by various signaling pathways that control the assembly and disassembly of three distinct, but functionally related actin and integrin-containing adhesion structures known as focal adhesions, podosomes, and invadopodia. In this review, we will discuss our current understanding of the similarities and differences between focal adhesions, podosomes, and invadopodia. We also will highlight several important tyrosine kinases and other signaling proteins that are known to control the formation and function of these adhesion structures, and we will discuss their role in pathophysiology.

\section{Focal Adhesions}

Focal adhesion formation and turnover has been used as a model system for understanding the mechanisms of cellular adhesion. Although focal adhesions, podosomes, and invadopodia share common signaling proteins, they are distinct in cellular architecture and function (summarized in Table 1). Focal adhesions, also known as "focal contacts," were identified over 30 years ago by electron microscopy and described as electron-dense plaques associated with actin filament bundles [10]. Focal adhesions can be considered to be large protein assembly complexes that spread mechanical forces from sites of cell adhesion to the cell body. In addition, focal adhesions regulate intracellular signaling pathways necessary for cell migration, growth, proliferation, embryogenesis, wound healing, and tissue repair [11-14]. Focal adhesions are comprised of a wide range of signaling proteins [15], such as the tyrosine kinases Pyk2 [16, 17], FAK $[18,19]$, Src [20, 21], Abl [22], and integrin-linked kinase [23]; the phosphatases PTP-PEST [24] and PTP1B [25]; the actin-binding proteins paxillin $[26,27]$, talin $[23,28-30]$, vinculin [23, 28-30] and tensin [31], the GTPases dynamin [32] and Cdc42/Rho [33, 34], as well as scaffolding proteins p130Cas [35] and Crk [27]. Many of these proteins have been shown to play predominantly a structural role or are involved in signal transduction [36].

Several protein kinases are recruited to focal adhesions upon cell attachment. These protein platforms recruit adaptor proteins and lead to the activation of complex network of signaling cascades that regulate basic cellular functions 

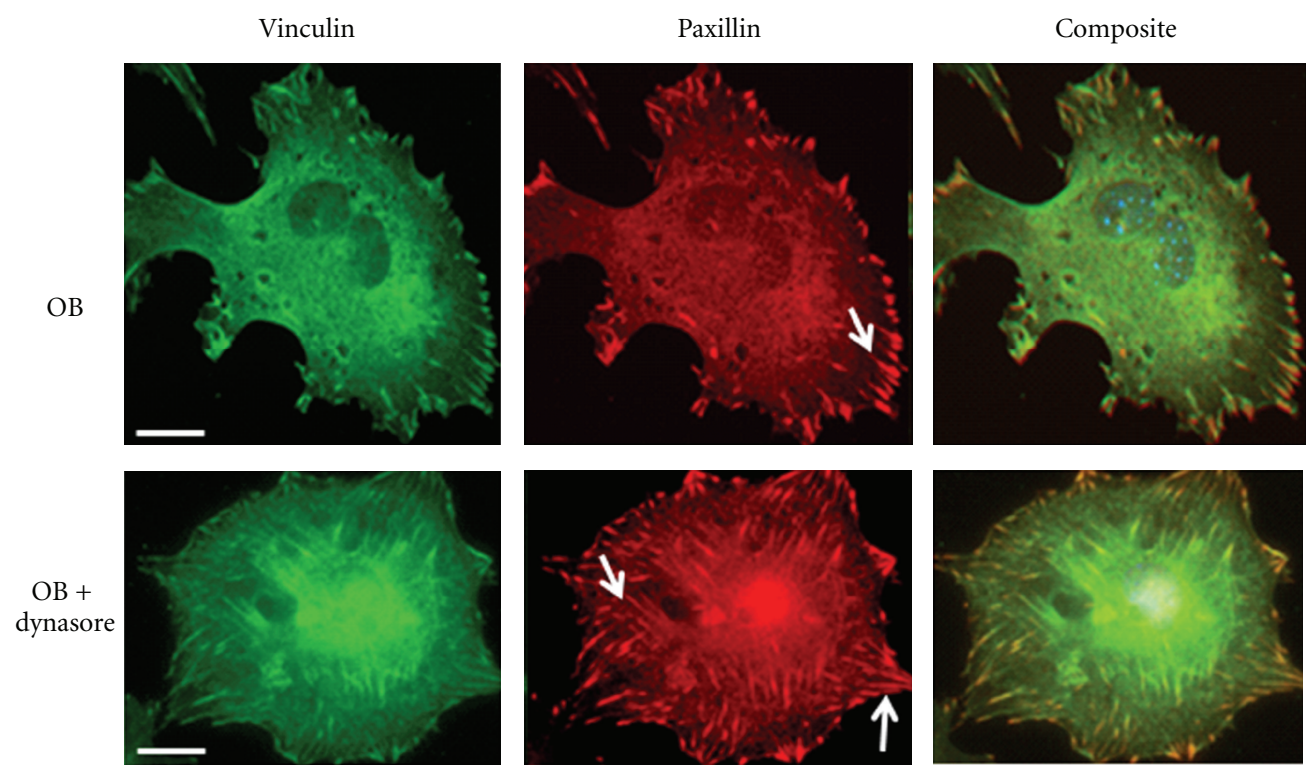

FIGURE 1: Inhibition of dynamin increases focal adhesions. Calvarial-derived osteoblasts (OBs) were treated with dynasore ( $90 \mu \mathrm{M})$ or vehicle for $1 \mathrm{hr}$ and labeled for vinculin (green) or paxillin (red). Green and red channels were merged to form the composite image. Scale bar indicates $10 \mu \mathrm{m}$. Arrows show location of focal adhesions.

$[16,36]$. An important tyrosine kinase found in focal adhesions is the focal adhesion kinase (FAK). FAK is a $125 \mathrm{kDa}$ cytoplasmic tyrosine kinase that is activated upon integrin engagement and controls signaling pathways crucial for cell proliferation, migration, and survival [37]. The C-terminal domain of FAK is known as the focal adhesion targeting domain (FAT). As its name implies, the FAT domain is involved in directing FAK to focal adhesion complexes in a variety of cells [38]. In contrast, the $\mathrm{N}$-terminal domain of FAK is known as the FERM domain ( $\mathrm{F}$ for the 4.1 protein, Ezrin, Radixin, and Moesin). The central kinase domain of FAK, which itself is activated by phosphorylation, directs the phosphorylation of several signaling protein such as paxillin, Grb2 and p130Cas [39]. In vitro studies have shown that the FERM binds directly to the intracellular domain of the $\beta 1$-integrin subunit and regulates FAK kinase activity [40]. It was also discovered that blocking $\beta 1$-integrin function leads to FAK dephosphorylation, which in turn increases the sensitivity of malignant tumors to ionizing radiation and delays the growth of human head and neck squamous cell carcinoma cell lines [41].

FAK and the tyrosine kinase Src play a central regulatory role in focal adhesion turnover, and deletion of either of these kinases increases focal adhesion stability [42]. In addition, it has been shown that FAK and Src work in concert with the GTPase dynamin to regulate microtubule-induced focal adhesion disassembly [43]. In studies by Ezratty and colleagues, FAK-/- fibroblasts exhibited reduced dynamin accumulation around focal adhesions compared to controls [43], suggesting that FAK regulates dynamin localization and recruitment to focal adhesions. In addition, Wang and others demonstrated that Src phosphorylates dynamin at tyrosine residues, which promotes the translocation of dynamin to focal adhesions by FAK [32]. Disruption of the Src-FAKdynamin complex blocked focal adhesion disassembly and fibroblast migration [32]. Using bone-forming osteoblasts as our model system, we also found that dynamin is expressed in osteoblasts and inhibition of its GTPase activity with the chemical inhibitor dynasore, increased the number of vinculin and paxillin-positive focal adhesions in osteoblasts, compared to control cells (Figure 1). Interestingly, we found that dynamin is also localized to actin-rich podosomes, in bone-resorbing osteoclasts $[44,45]$. Moreover, dynamin knockdown with shRNA or overexpression of a GTPaseinactive dynamin mutant increased podosome stability and the thickness of the podosome belt and decreased osteoclast bone resorbing activity [44]. Together, these studies reveal that dynamin's GTPase activity is necessary for both focal adhesion turnover in osteoblasts as well as podosome turnover in osteoclasts. Furthermore, these findings suggest potential similarities in the mechanism of turnover of focal adhesions and podosomes, which is likely to be dependent on the complement of signaling and scaffolding proteins present in different cell types.

\section{Podosomes}

Podosomes are highly dynamic adhesion structures found in a wide variety of migratory cells including macrophages, osteoclasts, endothelial cells [46-50], transformed fibroblasts [51], and carcinoma cell lines [52]. They were first identified in the 1980s in v-Src-transformed fibroblasts $[53,54]$. Podosomes and focal adhesions are both cellmatrix adhesion sites, but they differ in their structural design and turnover rates [55-59] (Table 1) despite sharing a large number of common signaling proteins, such as FAK, dynamin, talin, paxillin, Wasp, and vinculin [60]. Podosomes turnover occurs very rapidly with an apparent half-life of 2-12 min and involves the polymerization 


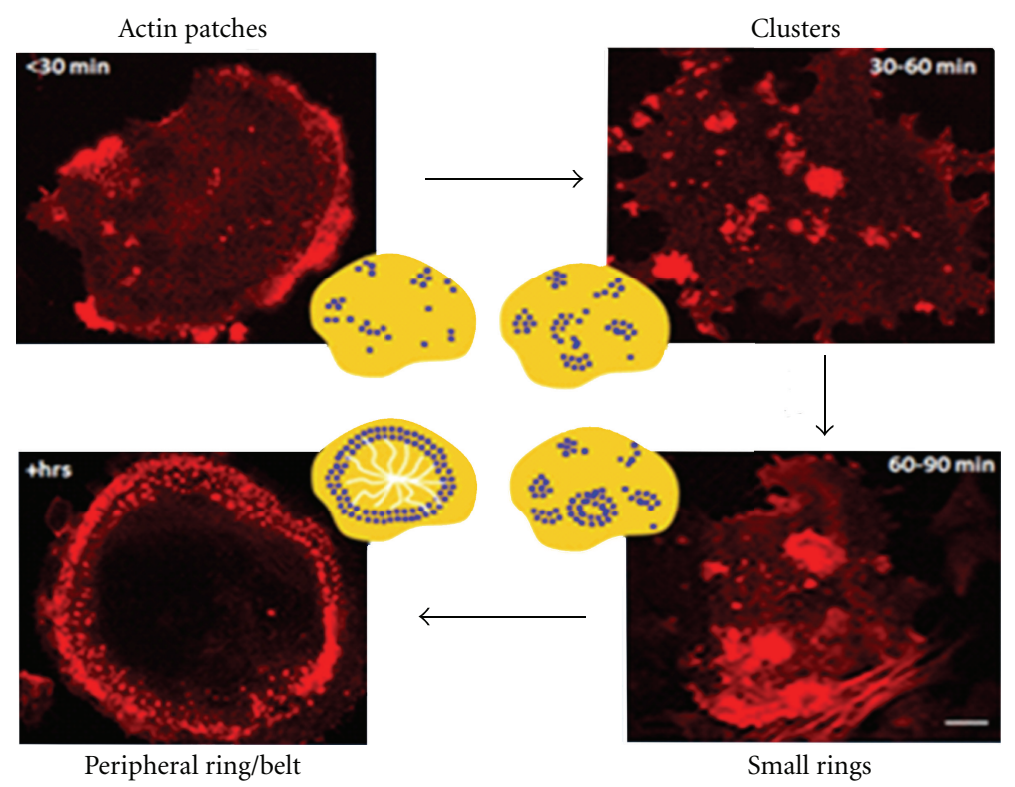

FIGURE 2: Dynamics of podosome organization in osteoclasts. Osteoclasts were generated from mouse bone marrow and plated on FBStreated coverslips for various times. Cells were fixed and stained with rhodamine phalloidin. Actin patches are found soon after osteoclast attachment. Actin patches then reorganize into small rings and then into a peripheral podosome belt. The podosome belt is stabilized by the microtubule network. Scale bar is $10 \mu \mathrm{m}$.

TABle 1: Common and unique features of focal adhesions, podosomes, and invadopodia. See text for details.

\begin{tabular}{|c|c|c|c|}
\hline & Focal adhesion & Podosomes & Invadopodia \\
\hline Appearance & dense plaques of F-actin & $\begin{array}{l}\text { F-actin bundle core surrounded by } \\
\text { actin cloud }\end{array}$ & $\begin{array}{l}\text { F-actin bundle core surrounded by actin } \\
\text { cloud }\end{array}$ \\
\hline Size & width: $2-6 \mu \mathrm{m}$ & $\begin{array}{l}\text { width: } 0.5-2 \mu \mathrm{m} \\
\text { length: } 0.5-2 \mu \mathrm{m}\end{array}$ & $\begin{array}{l}\text { width: } 0.5-2 \mu \mathrm{m} \\
\text { length: }>2 \mu \mathrm{m}\end{array}$ \\
\hline Duration (half-life) & hours & minutes & hours \\
\hline Cell expression & $\begin{array}{l}\text { numerous nonmigrating fibrob- } \\
\text { lastic cells }\end{array}$ & $\begin{array}{l}\text { monocytic cells } \\
\text { osteoclasts } \\
\text { endothelial cells } \\
\text { smooth muscle cells } \\
\text { Src-transformed fibroblasts }\end{array}$ & $\begin{array}{l}\text { carcinoma cells } \\
\text { Src-transformed fibroblasts }\end{array}$ \\
\hline Location & often found at leading edge of cell & ventral side of the cellular membrane & ventral side of the cellular membrane \\
\hline $\begin{array}{l}\text { Extracellular matrix } \\
\text { degradation }\end{array}$ & no & yes & yes \\
\hline $\begin{array}{l}\text { Common signaling } \\
\text { molecules }\end{array}$ & $\begin{array}{l}\text { focal adhesion proteins } \\
\text { GTPases } \\
\text { actin regulators } \\
\text { motor proteins } \\
\text { tyrosine kinases } \\
\text { phosphatases } \\
\text { scaffolding molecules }\end{array}$ & $\begin{array}{l}\text { focal adhesion proteins } \\
\text { GTPases } \\
\text { actin regulators } \\
\text { motor proteins } \\
\text { tyrosine kinases } \\
\text { phosphatases } \\
\text { scaffolding molecules }\end{array}$ & $\begin{array}{l}\text { focal adhesion proteins } \\
\text { GTPases } \\
\text { actin regulators } \\
\text { motor proteins } \\
\text { tyrosine kinases } \\
\text { phosphatases } \\
\text { scaffolding molecules }\end{array}$ \\
\hline Distinct Features & integrin receptors & $\begin{array}{l}\text { Integrin receptors } \\
\text { matrix-degrading enzymes }\end{array}$ & matrix-degrading enzymes \\
\hline
\end{tabular}

and depolymerization of the central F-actin core [50, 61]. Podosomes first appear as small actin dots which are then reorganized into small rings or rosettes with a diameter of $0.5-1 \mu \mathrm{m}$ and a depth of $0.2-0.4 \mu \mathrm{m}[62,63]$ (Figure 2). The assembly of podosomes in macrophages and osteoclasts is dependent on an intact microtubule system $[49,64]$. The central core of F-actin is surrounded by a ring of molecules that are involved in adhesion, matrix degradation, or migration. These proteins include the tyrosine kinases Pyk2 and Src [13], actin-associated proteins [51, 65], integrins [66], and their associated proteins [50], intermediate filaments [47], motor proteins [67] and metalloproteases $[50,68]$. In vitro studies demonstrated that RhoA, Rac1, and Cdc42 are also involved in the 
regulation of podosomes turnover $[69,70]$ and perhaps in recruiting podosomes to the leading edge of cells following microtubule-dependent cell polarization $[64,69,71-$ 73].

In contrast to focal adhesions, podosomes are found at sites of ECM degradation [51,74]. The metalloproteases MT1-MMP and MMP-9 have been localized to podosomes, strongly supporting a role for podosomes in ECM degradation $[56,68,75]$ in addition to adhesion [76]. This is well illustrated in osteoclasts, the primary bone-resorbing cells found in the body. In mature osteoclasts, podosomes are organized into a ring or belt-like structure at the cell periphery (referred to as the sealing zone) [50, 77]. This unique actin- and integrin-rich structure functions to dock osteoclasts to ECM proteins in bone and seals off the bone-resorbing compartment. This allows for the localized secretion of acidifying protons, chloride ions, and bone matrix-degrading metalloproteases [70].

In response to integrin engagement, and in the presence of intracellular calcium, Pyk2 is autophosphorylated at tyrosine residue Y402, which is essential for its catalytic activity $[37,78,79]$ and for downstream signaling via p130Cas, Src, $\mathrm{Cbl}$, integrins, gelsolin, and paxillin and the tyrosine phosphatase PTP-PEST [24, 80-82]. Pyk2 is expressed at high levels in the nervous system and in various hematopoietic cells $[57,83]$. Pyk2 is expressed in osteoblasts $[84,85]$ and osteoclasts [45, 64]. Deletion of Pyk2 in osteoblasts affects differentiation, migration, and actin remodeling $[84,85]$. In osteoclasts, Pyk2 is localized to the podosome belt and deletion of Pyk2 leads to a decrease in osteoclast bone resorption, which contributes to the osteopetrotic phenotype observed in Pyk2-deficient mice [64, 84]. Whereas deletion of Pyk2 in osteoblasts affects focal adhesion turnover (our unpublished findings), osteoclasts lacking Pyk2 exhibit structurally disorganized podosomes [64]. Src has also been shown to be indispensable for osteoclast function and is necessary for podosome assembly/disassembly [86, 87]. Osteoclasts lacking Src exhibit abnormal podosome rings, resulting in a dysfunctional sealing zone [88]. Leupaxin is a member of the focal adhesion-associated adaptor proteins and has been found to be associated with the podosome-belt (sealing zone) in osteoclasts $[89,90]$. It was also demonstrated that leupaxin forms a signaling complex with Pyk2, c-Src, and PTP-PEST which regulates the migration of prostate cancer cells [91]. Finally, as discussed above, the GTPase dynamin regulates podosome assembly and dynamics in osteoclasts [44, 63, 92] in a process that involves Src [44]. These studies and others demonstrate that distinct signaling proteins work in concert to regulate podosome organization and turnover in osteoclasts, and perhaps in podosome-containing migratory cells.

The tyrosine kinase Pyk2 is a homolog of FAK and shares $45 \%$ overall sequence identity and $60 \%$ amino acid identity within the catalytic domain. Structurally, Pyk2 also contains an N-terminal FERM domain, a central catalytic core, several proline rich domains (PRDs), and a C-terminal FAT domain $[64,79,93]$. The FERM domain is involved in localizing Pyk2 to the plasma membrane and facilitates Pyk2 binding to phosphatidylinositol bisphosphate (PIP2)
$[94,95]$. Although structural similarities exist between FAK and Pyk2, these proteins appear to exhibit unique effects on adhesion structures in different cells. Recently, it was reported that deletion of FAK in osteoclasts leads to the formation of peripheral podosome belt, whereas deletion of Pyk2 resulted in small podosome rings [96]. In addition, deletion of FAK but not Pyk2, in lung carcinoma CL1-5 cells resulted in decreased formation of podosomes rosettes [96]. These findings suggest that FAK and Pyk2 may regulate different patterning of podosome organization in osteoclasts [96]. Although the mechanism is unknown, the recruitment of downstream effector proteins is likely to be important in the differential roles of these kinases.

\section{Invadopodia}

Invadopodia appear as dynamic protrusions of the plasma membrane, containing a central actin core surrounded by adhesion proteins, signaling molecules, and scaffolding proteins [59]. In addition, invadopodia are sites of ECM degradation and are often observed in highly migratory metastatic cancer cells [57]. Invadopodia share, overlapping features with podosomes, especially with regards to their intracellular localization, composition of proteins, and cell types in which they are found $[55,59,62,97-99]$ (see Table 1). However, differences between invadopodia and podosomes do exist. In particular, podosomes are short lived (minutes) and found in phagocytic cells such as osteoclasts, whereas invadopdia persist for hours and found primarily in cancer cells $[97,100]$. Like podosomes, invadopodia are regulated by a multitude of signaling proteins such as the Src-family kinases, protein kinase C $[55,101-104]$, cdc42, NWASP, and Arp2/3 [105, 106]. Dynamin has also been shown to participate in focal extracellular matrix degradation by invasive cells [107]. Although integrin signaling in the initiation of podosome formation is well established, the role of integrins in invadopodia is not yet clear [108].

The life cycle of invadopodia involves initiation, extension, ECM degradation, and disassembly. Each of these steps involves F-actin remodeling and the activation/deactivation of signaling proteins around the central actin core. The initiation of invadopodia is known to be stimulated by EGF, PDGF and reactive oxygen species (ROS) [76]. Following initiation by EGF receptor activation, Src and the tyrosine kinase Abl (Abelson) are recruited and activated [102, $105,109]$. This results in an increase in actin polymerization and cortactin phosphorylation within the elongating invadopodium [102, 105, 109]. Microscopic imaging has shown that cortactin accumulates in invadopodia prior to F-actin nucleation [101], matrix metalloprotease accumulation, and matrix degradation [55], suggesting that cortactin isan early player in this process. In addition to the filamentous actin network, microtubules and intermediate filaments also participate in the elongation and extension of invadopodia [110], with the resulting structure resembling the arrangement of actin filaments in podosomes. The growing protrusive membrane is supplied by vesicular trafficking to sites of invadopodia extension and is controlled 
by the Golgi apparatus and by F-bar proteins such as CIP4 (cdc42 interacting protein) $[107,111]$ and the Ena/VASP family protein, Mena [112-114]. Membrane fusion and actin remodeling by dynamin have also been shown to be involved in invadopodia formation $[115,116]$. Like podosomes, the formation and stabilization of invadopodia involves microtubule-dependent transport $[108,110]$. The third step in the life cycle of invadopodia, and the major function of these structures, is ECM degradation. This function is shared with podosomes but is absent in focal adhesions. ECM degradation is facilitated by secretion of a variety of matrix metalloproteases and serine proteases [56, 112, $117,118]$ and is thought to be regulated by cortactin, an actin regulating protein [55]. The secreted proteases act to degrade components of the ECM, thereby facilitating cellular migration and invasion $[119,120]$. Finally, the disassembly of invadopodia involves depolymerization of the actin core [121] and has been shown to be regulated by ERK, paxillin, and the calcium-dependent cysteine protease, calpain, which degrades cortactin $[121,122]$.

The Src family kinases have been demonstrated to be critical for invadopodia formation and maturation. However, several lines of evidence support a role for Src in focal adhesion and podosome stability [123-125]. Similarly, as discussed above, FAK is important for focal adhesion turnover [126] but deletion of FAK has been also shown to increase invadopodia formation $[6,18]$ and suppress podosomes rosettes formation $\mathrm{n}$ fibroblasts [96]. Moreover, FAK has been shown to regulate a switch from phosphotyrosine-containing proteins at focal adhesions to invadopodia through the temporal regulation of active Src [6]. In the same study, it was shown that FAK-Src signaling also plays a significant role in cancer cell invasion $[6,116]$. The apparent overlapping role of FAK and Src in different adhesion structures can be explained by the formation of dynamic proteins complexes between these molecules. For example, the major autophosphorylation site in FAK is Y397 (Y402 in Pyk2) which serves as an SH2-binding site, allowing Src to bind FAK (or Pyk2) [127]. The binding of Src leads to release of its own autoinhibitory catalytic domain, leading to the full activation of Src and to the activation of distinct downstream signaling cascades [128].

\section{Adhesion Proteins and Human Disease}

In the following section, and summarized in Table 2, we provide an overview of the role of key focal adhesion proteins and their potential link to human diseases.

5.1. Skeletal Disease. Bones provide structural rigidity to the skeleton and are constantly remodeled to maintain calcium and mineral homeostasis and repair skeletal damage. Bone architectural integrity relies in part on the rate of apoptosis of bone-forming osteoblasts. The activity of Pyk2 is also linked with a variety of metabolic conditions, including the regulation of bone mass. Deletion of Pyk2 leads to increased bone mass in mice $[64,84]$ due in part to defects in focal adhesion signaling in osteoblasts (our unpublished findings) as well as changes in podosome dynamics in osteoclasts $[14,87]$. Src is also important for osteoclast function [129]. Deletion of Src impairs osteoclast bone resorbing activity and mice lacking Src exhibit severe osteopetrosis and exhibit defects in tooth eruption [129]. Studies have shown that disruption of the interaction of $\alpha$-actinin with integrins at focal adhesions increases osteoblast apoptosis, which shifts the balance in favor of osteoclast activity, resulting in bone loss [130].

5.2. Role in Cancer. As discussed above, invadopodia formation is tightly linked with cancer metastasis. For example, recently, it was demonstrated that the transcription factor Twist1, a central regulator of the epithelial mesenchymal transition, promotes invadopodia formation through upregulation of platelet-derived growth factor receptor expression and activity, which play significant role in human breast cancer metastasis [120]. Invadopodia formation and therefore cancer invasion also involves the adaptor proteins TKS4 and TKS5 (tyrosine kinase substrate 4 and 5) [131]. It was also found that TKS5 colocalizes to invadopodia in different human cancer cells and that decreased TKS5 expression leads to decreased podosome formation and to reduced tumor metastasis [132]. Thus, TKS4 and TKS5 could potentially be used as therapeutic targets for the treatment of certain types of cancer. Other studies have demonstrated that loss of function of the Fgd1 gene, which encodes a GTPexchange factor, was associated with a rare inherited human developmental disease called faciogenital dysplasia. Fgd1 mutations in humans cause skeletal and neurological effects. However, Fgd1 was also shown to be involved in invadopodia biogenesis and ECM degradation [133], and to be expressed in human prostate and breast cancer cells, suggesting it may also be critical for cancer progression and tumorigenesis.

Several independent studies have demonstrated a critical role for FAK in tumor progression and invasion. Elevated FAK phosphorylation has been observed in several cancers, including breast, colon, thyroid, prostate, oral, neck, and ovarian cancer $[134,135]$. Deletion of FAK from tumor cells or breast cancer cells resulted in decreased tumor progression $[136,137]$, while in endothelial-specific tamoxifen-inducible FAK knockout mice, tumor growth and angiogenesis were reduced [138], indicating that FAK may be important for tumorigenesis. In addition, quantitative real-time PCR has shown an elevation of FAK expression in malignant gastrointestinal stromal tumors [139]. Increased FAK expression was also detected in esophageal squamous cell carcinomas and was associated with cell differentiation, tumor invasiveness, and lymph node metastasis [140]. Also, it was found that FAK was overexpressed in esophageal squamous cell carcinoma which have led to cell differentiation, tumor invasiveness, and lymph node metastasis [140]. In vitro evidence also demonstrates that Src-FAK signaling is associated with elevated tumor cell metastases, invadopodia formation, and promotes cell invasion [141, 142]. The Src family of tyrosine kinases are important for embryonic stem cell self-renewal and are key regulators of signal transduction in various cells, including cancer 
TABLE 2: Signaling proteins and their link to adhesion structures and disease. ${ }^{+}$Humans mutations are associated with disease. Mutations in dynamin are linked to centronuclear myopathy and Charcot-Marie-Tooth neuropathy in humans. *Bone mass regulation is based on knockout mice studies. Other disease indications are predicted based on animal studies and in vitro studies. n/d: not determined. See text for details.

\begin{tabular}{|c|c|c|c|}
\hline Adhesion protein & Cell type & Adhesion structure & Disease indication \\
\hline \multirow{5}{*}{ FAK } & osteoblasts & focal adhesions & regulation of bone density* \\
\hline & osteoclasts & podosomes & regulation of bone density* \\
\hline & endothelial cells & podosomes? & angiogenesis \\
\hline & lung carcinoma cells & podosomes & cancer metastasis \\
\hline & various cancer cells & invadopodia & cancer metastasis \\
\hline \multirow{4}{*}{ Pyk2 } & osteoblasts & focal adhesions & regulation of bone density* \\
\hline & osteoclasts & podosomes & regulation of bone density* \\
\hline & endothelial cells & podosomes? & angiogenesis \\
\hline & various cancer cells & invadopodia & cancer metastasis \\
\hline \multirow{3}{*}{ Src } & osteoblasts & focal adhesions & regulation of bone density* \\
\hline & osteoclasts & podosomes & regulation of bone density* \\
\hline & various cancer cells & invadopodia & cancer metastasis \\
\hline \multirow{4}{*}{ Dynamin } & fibroblasts & focal adhesions & $\mathrm{n} / \mathrm{d}$ \\
\hline & osteoblasts & focal adhesions & regulation of bone density* \\
\hline & osteoclasts & podosomes & regulation of bone density* \\
\hline & neurons & $\mathrm{n} / \mathrm{d}$ & neuropathy $^{+}$ \\
\hline Twist1 & epithelial cells & invadopodia & cancer metastasis \\
\hline TKS4/5 & human cancer cells & invadopodia & cancer metastasis \\
\hline \multirow{2}{*}{ Leupaxin } & osteoclasts & podosomes & regulation of bone density* \\
\hline & cancer cells & invadopodia & cancer metastasis \\
\hline \multirow{2}{*}{ Fgd1 } & osteoblasts & focal adhesions? & skeletal abnormalities $^{+}$ \\
\hline & cancer cells & invadopodia & prostate and breast cancer metastasis \\
\hline
\end{tabular}

cells $[143,144]$. Collectively, these findings provide strong evidence that overexpression of FAK and other proteins localized to invadopodia are important for invadopodia formation and tumor metastasis. Although there is a strong correlation between the expression of FAK and Src in invadopodia and the potential link of these kinases in cancer progression and invasion, it is not yet clear if Src-FAK signaling specifically in invadopodia is critical role for tumor growth. Nevertheless, FAK may be a useful biomarker for cancer cell metastasis and inhibitors to FAK or Src may be useful to limit disease progression [145]. To this end, the FAK inhibitor PND-1186 was found to dramatically decrease FAK activity in breast carcinoma cells, resulting in tumor cell apoptosis [146].

Lung cancer is considered to be one of the leading causes of mortality among the malignant tumors worldwide. It has been reported that small cell lung cancers (SCLCs) constitute $15-25 \%$ of all newly diagnosed primary lung cancers [147]. In the same study, it was shown that inhibition of Pyk2 by lentiviral RNAi or Src using a chemical inhibitor (PP2) reduced SCLC survival and proliferation in liquid culture and in soft agar [147]. In addition, it was demonstrated that Pyk2 also plays an important role in human non-small cell lung cancer (NSCLC) [148]. This was based on the detection of higher levels of Pyk2, as determined by Western blotting and immunohistochemistry, in NSCLC biopsies compared to nontumors [148]. In other studies, FAK signaling was shown to be important in the early stages of mammary adenocarcinoma lung metastasis [149]. It was further demonstrated that the dominant-negative FAK inhibitor, FRNK, blocked lung metastasis if added one day before tumor cell injection, but had no effect if given several days after tumor cell injection [149]. Furthermore, it was demonstrated that depletion of FAK, but not Pyk2, in lung carcinoma CL1-5 cells, decreased the formation of podosome rosette structures and decreased cell invasion [96]. Nevertheless, despite strong in vitro and ex vivo evidence linking FAK, Pyk2, and Src to various cancers, a direct link between kinase activity, effects on podosome/invadopodia formation, and cancer cell metastasis/function is currently lacking.

Several studies also suggest a link between the adhesion kinases and prostate cancer. For example, it has been shown that metastatic prostate cancer cells express elevated FAK mRNA levels and protein phosphorylation [150]. More recent studies also suggest that inhibition of $\mathrm{Pyk} 2$ and FAK may be an important therapeutic strategy to decrease prostate cancer progression [151]. Sun et al. used a mouse xenograft model injected with a chemical inhibitor of FAK and Pyk2 (PF-562,271) [151]. After two weeks of treatment with PF-562,271 $(25 \mathrm{mg} / \mathrm{kg})$, the mouse xenograft model showed a $62 \%$ decrease in tumor growth, compared to control mice [151]. Leupaxin was found to associate with Pyk2, c-Src, and PTP-PEST. In vitro studies also suggest that the migration of prostate cancer cells (PC-3) may 
be regulated by protein complexes involving leupaxin, Pyk2, and the tyrosine phosphatase PTP-PEST, which dephosphorylates Pyk2 [91, 152]. Furthermore, it was shown that invasion of PC3 cells in a gelatin matrix is controlled by invadopodia and ECM degradation [153].

Astrocytomas represent the most common intracranial neoplasms accounting for $60 \%$ of all primary brain tumors. In separate studies, FAK and Pyk2 expressions have been shown to elevated in human brain astrocytomas [154-156]. In addition, a novel kinase inhibitor of FAK (TAE226) has been shown to increase tumor cell apoptosis in brain tumors [157]. Finally, others have demonstrated that administration of Src family kinase inhibitors, PP1 and Dasatinib, results in a dramatic increase in apoptosis of several pediatric brain tumor cell lines, compared to control cell lines was observed [158]. Collectively, the above findings suggest that inhibition of Pyk2 and FAK and other signaling molecules impair tumor migration by blocking the biogenesis of invadopodia which are important for ECM degradation.

5.3. Pulmonary and Other Diseases. Pyk2 was identified as a central regulator for angiogenesis of pulmonary vascular endothelial cells [159]. Additional studies show that Pyk2 is essential in regulating airway inflammation, Th2 cytokine secretion, and airway hyper-responsiveness in ovalbuminsensitized mice during antigen challenge in vivo [160]. Inhibition of Pyk2 blocked broncho-alveolar lavage, eosinophilia, mucous gland hyperplasia, and airway hyper-responsiveness, conditions that are also characteristic of the asthmatic state in humans. In addition, deletion of Pyk2 leads to developmental defects, abnormal macrophage activity, obesity, and insulin resistance under a high-fat diet $[161,162]$. Pyk2 activity in the heart may also protect against arrhythmia [163]. Although the mechanism by which Pyk2 regulates these physiological processes is still unknown, therapeutic strategies that target Pyk2 might be a novel approach for the treatment of a variety of metabolic and pathological diseases. Finally, it has been shown that dynamin mutations are associated with human centronuclear myopathy and Charcot-Marie-Tooth neuropathy [164-166]. These diseases are currently attributed to defects in dynamin-mediated endocytosis. However, it is interest to note that dynamin plays an important role in actin remodeling, which is linked to its function in membrane endocytosis $[115,116]$. Therefore, it is possible that dynamin's role in actin remodeling and adhesion structure turnover $[43,44,63,92,107]$ may also be involved in these pathologies, although this remains to be determined.

\section{Summary and Perspectives}

In summary, focal adhesions, podosomes, and invadopodia facilitate adhesion to the matrix and cellular migration. In addition to adhesion, podosomes and invadopodia have evolved the unique function of ECM degradation. The focal adhesion kinases, FAK and Pyk2, exhibit overlapping and unique roles in the biogenesis, stability, and disassembly of these different adhesion structures. There is currently a growing body of evidence linking these and other kinases to the biogenesis of different adhesion structures. In addition, a great deal of studies suggests a link between the expression levels of these kinases and several human diseases, especially cancer (see Table 2). Finally, emerging evidence suggests that disrupting the activity of the adhesion kinases not only disrupts the formation of the adhesion structures, but it may also be useful in the treatment of serious medical conditions such as cancer and osteoporosis. A greater understanding of the function of adhesion kinases and the adhesion structures they control will offer future avenues for therapeutic interventions against several human diseases.

\section{Abbreviations}

$\begin{array}{ll}\text { ECM: } & \text { Extracellular matrix } \\ \text { OC: } & \text { Osteoclast } \\ \text { OB: } & \text { Osteoblast } \\ \text { FAK: } & \text { Focal adhesion kinase } \\ \text { SCLC: } & \text { Small cell lung cancer } \\ \text { NSCLC: } & \text { Nonsmall cell lung cancer. }\end{array}$

\section{References}

[1] E. Hohenester and J. Engel, "Domain structure and organisation in extracellular matrix proteins," Matrix Biology, vol. 21, no. 2, pp. 115-128, 2002.

[2] R. O. Hynes, "The extracellular matrix: not just pretty fibrils," Science, vol. 326, no. 5957, pp. 1216-1219, 2009.

[3] P. D. Yurchenco and B. L. Patton, "Developmental and pathogenic mechanisms of basement membrane assembly," Current Pharmaceutical Design, vol. 15, no. 12, pp. 12771294, 2009.

[4] B. Geiger, A. Bershadsky, R. Pankov, and K. M. Yamada, "Transmembrane extracellular matrix-cytoskeleton crosstalk," Nature Reviews Molecular Cell Biology, vol. 2, no. 11, pp. 793-805, 2001.

[5] H. C. Slavkin, "Combinatorial process for extracellular matrix influences on gene expression: a hypothesis," Journal of Craniofacial Genetics and Developmental Biology, vol. 2, no. 2, pp. 179-189, 1982.

[6] K. T. Chan, C. L. Cortesio, and A. Huttenlocher, "Fak alters invadopodia and focal adhesion composition and dynamics to regulate breast cancer invasion," The Journal of Cell Biology, vol. 185, no. 2, pp. 357-370, 2009.

[7] E. D. Hay, "Extracellular matrix," The Journal of Cell Biology, vol. 91, no. 3, part 2, pp. 205s-223s, 1981.

[8] C. H. Damsky, "Extracellular matrix-integrin interactions in osteoblast function and tissue remodeling," Bone, vol. 25, no. 1, pp. 95-96, 1999.

[9] A. De Arcangelis and E. Georges-Labouesse, "Integrin and ECM functions: roles in vertebrate development," Trends in Genetics, vol. 16, no. 9, pp. 389-395, 2000.

[10] M. Abercrombie, J. E. M. Heaysman, and S. M. Pegrum, “The locomotion of fibroblasts in culture. IV. Electron microscopy of the leading lamella," Experimental Cell Research, vol. 67, no. 2, pp. 359-367, 1971.

[11] M. A. Wozniak, K. Modzelewska, L. Kwong, and P. J. Keely, "Focal adhesion regulation of cell behavior," Biochimica et Biophysica Acta, vol. 1692, no. 2-3, pp. 103-119, 2004.

[12] R. O. Hynes, "Integrins: versatility, modulation, and signaling in cell adhesion," Cell, vol. 69, no. 1, pp. 11-25, 1992. 
[13] M. A. Schwartz, M. D. Schaller, and M. H. Ginsberg, "Integrins: emerging paradigms of signal transduction," Annual Review of Cell and Developmental Biology, vol. 11, pp. 549-599, 1995.

[14] L. H. Romer, K. G. Birukov, and J. G. N. Garcia, "Focal adhesions: paradigm for a signaling nexus," Circulation Research, vol. 98, no. 5, pp. 606-616, 2006.

[15] R. Zaidel-Bar, S. Itzkovitz, A. Ma'ayan, R. Iyengar, and B. Geiger, "Functional atlas of the integrin adhesome," Nature Cell Biology, vol. 9, no. 8, pp. 858-867, 2007.

[16] E. Zamir and B. Geiger, "Components of cell-matrix adhesions," Journal of Cell Science, vol. 114, no. 20, pp. 3577-3579, 2001.

[17] Q. S. Du, X. R. Ren, Y. Xie, Q. Wang, L. Mei, and W. C. Xiong, "Inhibition of PYK2-induced actin cytoskeleton reorganization, PYK2 autophosphorylation and focal adhesion targeting by FAK," Journal of Cell Science, vol. 114, no. 16, pp. 2977-2987, 2001.

[18] D. Ilic, Y. Furuta, S. Kanazawa et al., "Reduced cell motility and enhanced focal adhesion contact formation in cells from FAK-deficient mice," Nature, vol. 377, no. 6549, pp. 539-544, 1995.

[19] H. B. Wang, M. Dembo, S. K. Hanks, and Y. L. Wang, "Focal adhesion kinase is involved in mechanosensing during fibroblast migration," Proceedings of the National Academy of Sciences of the United States of America, vol. 98, no. 20, pp. 11295-11300, 2001.

[20] D. M. Suter and P. Forscher, "Transmission of growth cone traction force through apCAM-cytoskeletal linkages is regulated by Src family tyrosine kinase activity," The Journal of Cell Biology, vol. 155, no. 4, pp. 427-438, 2001.

[21] M. C. Frame, V. J. Fincham, N. O. Carragher, and J. A. Wyke, "V-Src's hold over actin and cell adhesions," Nature Reviews Molecular Cell Biology, vol. 3, no. 4, pp. 233-245, 2002.

[22] E. Zamir and B. Geiger, "Molecular complexity and dynamics of cell-matrix adhesions," Journal of Cell Science, vol. 114, no. 20, pp. 3583-3590, 2001.

[23] C. Grashoff, I. Thievessen, K. Lorenz, S. Ussar, and R. Fässler, "Integrin-linked kinase: integrin's mysterious partner," Current Opinion in Cell Biology, vol. 16, no. 5, pp. 565-571, 2004.

[24] A. Angers-Loustau, J. F. Côté, A. Charest et al., "Protein tyrosine phosphatase-PEST regulates focal adhesion disassembly, migration, and cytokinesis in fibroblasts," The Journal of Cell Biology, vol. 144, no. 5, pp. 1019-1031, 1999.

[25] A. Bourdeau, N. Dubé, and M. L. Tremblay, "Cytoplasmic protein tyrosine phosphatases, regulation and function: the roles of PTP1B and TC-PTP," Current Opinion in Cell Biology, vol. 17, no. 2, pp. 203-209, 2005.

[26] C. E. Turner, "Paxillin and focal adhesion signalling," Nature Cell Biology, vol. 2, no. 12, pp. E231-E236, 2000.

[27] H. Yano, H. Uchida, T. Iwasaki et al., "Paxillin $\alpha$ and Crk-associated substrate exert opposing effects on cell migration and contact inhibition of growth through tyrosine phosphorylation," Proceedings of the National Academy of Sciences of the United States of America, vol. 97, no. 16, pp. 9076-9081, 2000.

[28] K. A. DeMali, C. A. Barlow, and K. Burridge, "Recruitment of the Arp $2 / 3$ complex to vinculin: coupling membrane protrusion to matrix adhesion," The Journal of Cell Biology, vol. 159, no. 5, pp. 881-891, 2002.

[29] I. D. Campbell and M. H. Ginsberg, "The talin-tail interaction places integrin activation on FERM ground," Trends in Biochemical Sciences, vol. 29, no. 8, pp. 429-435, 2004.
[30] D. R. Critchley, "Genetic, biochemical and structural approaches to talin function," Biochemical Society Transactions, vol. 33, no. 6, pp. 1308-1312, 2005.

[31] S. H. Lo, “Tensin," The International Journal of Biochemistry and Cell Biology, vol. 36, no. 1, pp. 31-34, 2004.

[32] Y. Wang, H. Cao, J. Chen, and M. A. McNiven, "A direct interaction between the large GTPase dynamin-2 and FAK regulates focal adhesion dynamics in response to active Src," Molecular Biology of the Cell, vol. 22, no. 9, pp. 1529-1538, 2011.

[33] C. D. Nobes and A. Hall, "Rho, Rac, and Cdc42 GTPases regulate the assembly of multimolecular focal complexes associated with actin stress fibers, lamellipodia, and filopodia," Cell, vol. 81, no. 1, pp. 53-62, 1995.

[34] K. Burridge and K. Wennerberg, "Rho and Rac take center stage," Cell, vol. 116, no. 2, pp. 167-179, 2004.

[35] L. A. Cary, D. C. Han, T. R. Polte, S. K. Hanks, and J. L. Guan, "Identification of p130(Cas) as a mediator of focal adhesion kinase-promoted cell migration," The Journal of Cell Biology, vol. 140, no. 1, pp. 211-221, 1998.

[36] B. Geiger, J. P. Spatz, and A. D. Bershadsky, "Environmental sensing through focal adhesions," Nature Reviews Molecular Cell Biology, vol. 10, no. 1, pp. 21-33, 2009.

[37] S. K. Mitra, D. A. Hanson, and D. D. Schlaepfer, "Focal adhesion kinase: in command and control of cell motility," Nature Reviews Molecular Cell Biology, vol. 6, no. 1, pp. 56-68, 2005.

[38] J. D. Hildebrand, M. D. Schaller, and J. T. Parsons, "Identification of sequences required for the efficient localization of the focal adhesion kinase, pp125(FAK), to cellular focal adhesions," The Journal of Cell Biology, vol. 123, no. 4, pp. 993-1005, 1993.

[39] J. W. Thomas, M. A. Cooley, J. M. Broome et al., "The role of focal adhesion kinase binding in the regulation of tyrosine phosphorylation of paxillin," The Journal of Biological Chemistry, vol. 274, no. 51, pp. 36684-36692, 1999.

[40] M. D. Schaller, C. A. Otey, J. D. Hildebrand, and J. T. Parsons, "Focal adhesion kinase and paxillin bind to peptides mimicking $\beta$ integrin cytoplasmic domains," The Journal of Cell Biology, vol. 130, no. 5, pp. 1181-1187, 1995.

[41] I. Eke, Y. Deuse, S. Hehlgans et al., " $\beta(1)$ Integrin/ FAK/cortactin signaling is essential for human head and neck cancer resistance to radiotherapy," The Journal of Clinical Investigation, vol. 122, no. 4, pp. 1529-1540, 2012.

[42] M. G. Yeo, M. A. Partridge, E. J. Ezratty, Q. Shen, G. G. Gundersen, and E. E. Marcantonio, "Src SH2 arginine 175 is required for cell motility: specific focal adhesion kinase targeting and focal adhesion assembly function," Molecular and Cellular Biology, vol. 26, no. 12, pp. 4399-4409, 2006.

[43] E. J. Ezratty, M. A. Partridge, and G. G. Gundersen, "Microtubule-induced focal adhesion disassembly is mediated by dynamin and focal adhesion kinase," Nature Cell Biology, vol. 7, no. 6, pp. 581-590, 2005.

[44] A. Bruzzaniti, L. Neff, A. Sanjay, W. C. Horne, P. De Camilli, and R. Baron, "Dynamin forms a Src kinase-sensitive complex with $\mathrm{Cbl}$ and regulates podosomes and osteoclast activity," Molecular Biology of the Cell, vol. 16, no. 7, pp. 3301-3313, 2005.

[45] A. Bruzzaniti, L. Neff, A. Sandoval, L. Du, W. C. Horne, and R. Baron, "Dynamin reduces Pyk2 Y402 phosphorylation and Src binding in osteoclasts," Molecular and Cellular Biology, vol. 29, no. 13, pp. 3644-3656, 2009.

[46] P. A. Amato, E. R. Unanue, and D. L. Taylor, "Distribution of actin in spreading macrophages: a comparative study on 
living and fixed cells," The Journal of Cell Biology, vol. 96, no. 3, pp. 750-761, 1983.

[47] P. C. Marchisio, D. Cirillo, L. Naldini, M. V. Primavera, A. Teti, and A. Zambonin-Zallone, "Cell-substratum interaction of cultured avian osteoclasts is mediated by specific adhesion structures," The Journal of Cell Biology, vol. 99, no. 5, pp. 1696-1705, 1984.

[48] J. Wang, Y. Taba, J. Pang, G. Yin, C. Yan, and B. C. Berk, “GIT1 mediates vegf-induced podosome formation in endothelial cells. Critical role for PLCy," Arteriosclerosis, Thrombosis, and Vascular Biology, vol. 29, no. 2, pp. 202-208, 2009.

[49] S. Linder, K. Hufner, U. Wintergerst, and M. Aefelbacher, "Microtubule-dependent formation of podosomal adhesion structures in primary human macrophages," Journal of Cell Science, vol. 113, no. 23, pp. 4165-4176, 2000.

[50] O. Destaing, F. Saltel, J. C. Géminard, P. Jurdic, and F. Bard, "Podosomes display actin turnover and dynamic self-organization in osteoclasts expressing actin-green fluorescent protein," Molecular Biology of the Cell, vol. 14, no. 2, pp. 407-416, 2003.

[51] K. Mizutani, H. Miki, H. He, H. Maruta, and T. Takenawa, "Essential role of neural Wiskott-Aldrich syndrome protein in podosome formation and degradation of extracellular matrix in Src-transformed fibroblasts," Cancer Research, vol. 62, no. 3, pp. 669-674, 2002.

[52] H. M. Kocher, J. Sandle, T. A. Mirza, N. F. Li, and I. R. Hart, "Ezrin interacts with cortactin to form podosomal rosettes in pancreatic cancer cells," Gut, vol. 58, no. 2, pp. 271-284, 2009.

[53] W. T. Chen, "Proteolytic activity of specialized surface protrusions formed at rosette contact sites of transformed cells," Journal of Experimental Zoology, vol. 251, no. 2, pp. 167-185, 1989.

[54] G. Tarone, D. Cirillo, and F. G. Giancotti, "Rous-sarcoma virus-transformed fibroblasts adhere primarily at discrete protrusions of the ventral membrane called podosomes," Experimental Cell Research, vol. 159, no. 1, pp. 141-157, 1985.

[55] V. V. Artym, Y. Zhang, F. Seillier-Moiseiwitsch, K. M. Yamada, and S. C. Mueller, "Dynamic interactions of cortactin and membrane type 1 matrix metalloproteinase at invadopodia: defining the stages of invadopodia formation and function," Cancer Research, vol. 66, no. 6, pp. 3034-3043, 2006.

[56] E. S. Clark, A. S. Whigham, W. G. Yarbrough, and A. M. Weaver, "Cortactin is an essential regulator of matrix metalloproteinase secretion and extracellular matrix degradation in invadopodia," Cancer Research, vol. 67, no. 9, pp. 4227-4235, 2007.

[57] S. Linder and P. Kopp, "Podosomes at a glance," Journal of Cell Science, vol. 118, no. 10, pp. 2079-2082, 2005.

[58] M. Gimona, R. Buccione, S. A. Courtneidge, and S. Linder, "Assembly and biological role of podosomes and invadopodia," Current Opinion in Cell Biology, vol. 20, no. 2, pp. 235-241, 2008.

[59] D. A. Murphy and S. A. Courtneidge, "The "ins" and "outs" of podosomes and invadopodia: characteristics, formation and function," Nature Reviews Molecular Cell Biology, vol. 12, no. 7, pp. 413-426, 2011.

[60] M. R. Block, C. Badowski, A. Millon-Fremillon et al., "Podosome-type adhesions and focal adhesions, so alike yet so different," European Journal of Cell Biology, vol. 87, no. 8-9, pp. 491-506, 2008.

[61] P. Jurdic, F. Saltel, A. Chabadel, and O. Destaing, "Podosome and sealing zone: specificity of the osteoclast model,"
European Journal of Cell Biology, vol. 85, no. 3-4, pp. 195-202, 2006.

[62] R. Buccione, J. D. Orth, and M. A. McNiven, "Foot and mouth: podosomes, invadopodia and circular dorsal ruffles," Nature Reviews Molecular Cell Biology, vol. 5, no. 8, pp. 647-657, 2004.

[63] M. A. McNiven, M. Baldassarre, and R. Buccione, "The role of dynamin in the assembly and function of podosomes and invadopodia," Frontiers in Bioscience, vol. 9, pp. 1944-1953, 2004.

[64] H. Gil-Henn, O. Destaing, N. A. Sims et al., "Defective microtubule-dependent podosome organization in osteoclasts leads to increased bone density in Pyk $2^{-/-}$mice," The Journal of Cell Biology, vol. 178, no. 6, pp. 1053-1064, 2007.

[65] Y. Furuta, D. Ilic, S. Kanazawa, N. Takeda, T. Yamamoto, and S. Aizawa, "Mesodermal defect in late phase of gastrulation by a targeted mutation of focal adhesion kinase, FAK," Oncogene, vol. 11, no. 10, pp. 1989-1995, 1995.

[66] M. Pfaff and P. Jurdic, "Podosomes in osteoclast-like cells: structural analysis and cooperative roles of paxillin, prolinerich tyrosine kinase 2 (Pyk2) and integrin $\alpha \mathrm{V} \beta 3$," Journal of Cell Science, vol. 114, no. 15, pp. 2775-2786, 2001.

[67] V. Betapudi, "Myosin II motor proteins with different functions determine the fate of lamellipodia extension during cell spreading," PLoS ONE, vol. 5, no. 1, Article ID e8560, 2010.

[68] T. Sato, M. D. C. Ovejero, P. Hou et al., "Identification of the membrane-type matrix metalloproteinase MT1-MMP in osteoclasts," Journal of Cell Science, vol. 110, no. 5, pp. 589-596, 1997.

[69] S. Burns, A. J. Thrasher, M. P. Blundell, L. Machesky, and G. E. Jones, "Configuration of human dendritic cell cytoskeleton by Rho GTPases, the WAS protein, and differentiation,” Blood, vol. 98, no. 4, pp. 1142-1149, 2001.

[70] C. Itzstein, F. P. Coxon, and M. J. Rogers, "The regulation of osteoclast function and bone resorption by small GTPases," Small GTPases, vol. 2, no. 3, pp. 117-130, 2011.

[71] S. F. G. van Helden and P. L. Hordijk, "Podosome regulation by Rho GTPases in myeloid cells," European Journal of Cell Biology, vol. 90, no. 2-3, pp. 189-197, 2011.

[72] S. Ory, H. Brazier, G. Pawlak, and A. Blangy, "Rho GTPases in osteoclasts: orchestrators of podosome arrangement," European Journal of Cell Biology, vol. 87, no. 8-9, pp. 469-477, 2008.

[73] G. Giannone, G. Jiang, D. H. Sutton, D. R. Critchley, and M. P. Sheetz, "Talin1 is critical for force-dependent reinforcement of initial integrin-cytoskeleton bonds but not tyrosine kinase activation," The Journal of Cell Biology, vol. 163, no. 2, pp. 409-419, 2003.

[74] V. V. Artym, K. M. Yamada, and S. C. Mueller, "ECM degradation assays for analyzing local cell invasion," Methods in Molecular Biology, vol. 522, pp. 211-219, 2009.

[75] J. M. Delaissé, M. T. Engsig, V. Everts et al., "Proteinases in bone resorption: obvious and less obvious roles," Clinica Chimica Acta, vol. 291, no. 2, pp. 223-234, 2000.

[76] S. Linder and M. Aepfelbacher, "Podosomes: adhesion hot-spots of invasive cells," Trends in Cell Biology, vol. 13, no. 7, pp. 376-385, 2003.

[77] S. Hu, E. Planus, D. Georgess et al., "Podosome rings generate forces that drive saltatory osteoclast migration," Molecular Biology of the Cell, vol. 22, no. 17, pp. 3120-3126, 2011.

[78] I. Dikic, G. Tokiwa, S. Lev, S. A. Courtneidge, and J. Schlessinger, "A role for Pyk2 and Src in linking G-proteincoupled receptors with MAP kinase activation," Nature, vol. 383, no. 6600, pp. 547-550, 1996. 
[79] H. Avraham, S. Y. Park, K. Schinkmann, and S. Avraham, "RAFTK/Pyk2-mediated cellular signalling," Cellular Signalling, vol. 12, no. 3, pp. 123-133, 2000.

[80] D. Davidson and A. Veillette, "PTP-PEST, a scaffold protein tyrosine phosphatase, negatively regulates lymphocyte activation by targeting a unique set of substrates," The EMBO Journal, vol. 20, no. 13, pp. 3414-3426, 2001.

[81] Y. Shen, G. Schneider, J. F. Cloutier, A. Veillette, and M. D. Schaller, "Direct association of protein-tyrosine phosphatase PTP-PEST with paxillin," The Journal of Biological Chemistry, vol. 273, no. 11, pp. 6474-6481, 1998.

[82] C. E. Turner, "Paxillin interactions," Journal of Cell Science, vol. 113, no. 23, pp. 4139-4140, 2000.

[83] S. Avraham, R. London, Y. Fu et al., "Identification and characterization of a novel related adhesion focal tyrosine kinase (RAFTK) from megakaryocytes and brain," The Journal of Biological Chemistry, vol. 270, no. 46, pp. 27742-27751, 1995.

[84] L. Buckbinder, D. T. Crawford, H. Qi et al., "Proline-rich tyrosine kinase 2 regulates osteoprogenitor cells and bone formation, and offers an anabolic treatment approach for osteoporosis," Proceedings of the National Academy of Sciences of the United States of America, vol. 104, no. 25, pp. 10619-10624, 2007.

[85] M. A. Kacena, P. P. Eleniste, Y. H. Cheng et al., "Megakaryocytes regulate expression of Pyk2 isoforms and caspasemediated cleavage of actin in osteoblasts," The Journal of Biological Chemistry, vol. 287, no. 21, pp. 17257-17268, 2012.

[86] L. T. Duong, P. T. Lakkakorpi, I. Nakamura, M. Machwate, R. M. Nagy, and G. A. Rodan, "PYK2 in osteoclasts is an adhesion kinase, localized in the sealing zone, activated by ligation of $\alpha(\mathrm{v}) \beta 3$ integrin, and phosphorylated by Src kinase," Journal of Clinical Investigation, vol. 102, no. 5, pp. 881-892, 1998.

[87] A. Sanjay, A. Houghton, L. Neff et al., "Cbl associates with Pyk 2 and Src to regulate Src kinase activity, $\alpha \mathrm{v} \beta 3$ integrinmediated signaling, cell adhesion, and osteoclast motility," The Journal of Cell Biology, vol. 152, no. 1, pp. 181-195, 2001.

[88] O. Destaing, A. Sanjay, C. Itzstein et al., "The tyrosine kinase activity of c-Src regulates actin dynamics and organization of podosomes in osteoclasts," Molecular Biology of the Cell, vol. 19, no. 1, pp. 394-404, 2008.

[89] A. Gupta, B. S. Lee, M. A. Khadeer et al., "Leupaxin is a critical adaptor protein in the adhesion zone of the osteoclast," Journal of Bone and Mineral Research, vol. 18, no. 4, pp. 669-685, 2003.

[90] S. N. Sahu, M. A. Khadeer, B. W. Robertson, S. M. Núñez, G. Bai, and A. Gupta, "Association of leupaxin with Src in osteoclasts," American Journal of Physiology, vol. 292, no. 1, pp. C581-C590, 2007.

[91] S. N. Sahu, S. Nunez, G. Bai, and A. Gupta, "Interaction of Pyk2 and PTP-PEST with leupaxin in prostate cancer cells," American Journal of Physiology, vol. 292, no. 6, pp. C2288-C2296, 2007.

[92] G. C. Ochoa, V. I. Slepnev, L. Neff et al., "A functional link between dynamin and the actin cytoskeleton at podosomes," The Journal of Cell Biology, vol. 150, no. 2, pp. 377-389, 2000.

[93] S. Han, A. Mistry, J. S. Chang et al., "Structural characterization of proline-rich tyrosine kinase 2 (PYK2) reveals a unique (DFG-out) conformation and enables inhibitor design," The Journal of Biological Chemistry, vol. 284, no. 19, pp. 13193-13201, 2009.

[94] A. H. Chishti, A. C. Kim, S. M. Marfatia et al., "The FERM domain: a unique module involved in the linkage of cytoplasmic proteins to the membrane," Trends in Biochemical Sciences, vol. 23, no. 8, pp. 281-282, 1998.
[95] K. Hamada, T. Shimizu, T. Matsui, S. Tsukita, S. Tsukita, and T. Hakoshima, "Structural basis of the membrane-targeting and unmasking mechanisms of the radixin FERM domain," The EMBO Journal, vol. 19, no. 17, pp. 4449-4462, 2000.

[96] Y. R. Pan, C. L. Chen, and H. C. Chen, "FAK is required for the assembly of podosome rosettes," The Journal of Cell Biology, vol. 195, no. 1, pp. 113-129, 2011.

[97] I. Ayala, M. Baldassarre, G. Caldieri, and R. Buccione, "Invadopodia: a guided tour," European Journal of Cell Biology, vol. 85, no. 3-4, pp. 159-164, 2006.

[98] S. Linder, "The matrix corroded: podosomes and invadopodia in extracellular matrix degradation," Trends in Cell Biology, vol. 17, no. 3, pp. 107-117, 2007.

[99] S. Linder, "Invadosomes at a glance," Journal of Cell Science, vol. 122, no. 17, pp. 3009-3013, 2009.

[100] M. Vicente-Manzanares and A. R. Horwitz, "Cell migration: an overview," Methods in Molecular Biology, vol. 769, pp. $1-24,2011$.

[101] I. Ayala, M. Baldassarre, G. Giacchetti et al., "Multiple regulatory inputs converge on cortactin to control invadopodia biogenesis and extracellular matrix degradation," Journal of Cell Science, vol. 121, no. 3, pp. 369-378, 2008.

[102] S. Tehrani, N. Tomasevic, S. Weed, R. Sakowicz, and J. A. Cooper, "Src phosphorylation of cortactin enhances actin assembly," Proceedings of the National Academy of Sciences of the United States of America, vol. 104, no. 29, pp. 11933-11938, 2007.

[103] M. Marzia, R. Chiusaroli, L. Neff et al., "Calpain is required for normal osteoclast function and is down-regulated by calcitonin," The Journal of Biological Chemistry, vol. 281, no. 14, pp. 9745-9754, 2006.

[104] S. S. Stylli, T. T. I. Stacey, A. M. Verhagen et al., "Nck adaptor proteins link Tks5 to invadopodia actin regulation and ECM degradation," Journal of Cell Science, vol. 122, no. 15, pp. 2727-2740, 2009.

[105] C. C. Mader, M. Oser, M. A. O. Magalhaes et al., "An EGFRSrc-Arg-cortactin pathway mediates functional maturation of invadopodia and breast cancer cell invasion," Cancer Research, vol. 71, no. 5, pp. 1730-1741, 2011.

[106] T. Uruno, J. Liu, P. Zhang et al., "Activation of Arp $2 / 3$ complex-mediated actin polymerization by cortactin," Nature Cell Biology, vol. 3, no. 3, pp. 259-266, 2001.

[107] M. Baldassarre, A. Pompeo, G. Beznoussenko et al., "Dynamin participates in focal extracellular matrix degradation by invasive cells," Molecular Biology of the Cell, vol. 14, no. 3, pp. 1074-1084, 2003.

[108] S. Linder, C. Wiesner, and M. Himmel, "Degrading devices: invadosomes in proteolytic cell invasion," Annual Review of Cell and Developmental Biology, vol. 27, pp. 185-211, 2011.

[109] F. Kimura, K. Iwaya, T. Kawaguchi et al., "Epidermal growth factor-dependent enhancement of invasiveness of squamous cell carcinoma of the breast," Cancer Science, vol. 101, no. 5, pp. 1133-1140, 2010.

[110] M. Schoumacher, R. D. Goldman, D. Louvard, and D. M. Vignjevic, "Actin, microtubules, and vimentin intermediate filaments cooperate for elongation of invadopodia," The Journal of Cell Biology, vol. 189, no. 3, pp. 541-556, 2010.

[111] C. S. Pichot, C. Arvanitis, S. M. Hartig et al., "Cdc42interacting protein 4 promotes breast cancer cell invasion and formation of invadopodia through activation of N-WASp," Cancer Research, vol. 70, no. 21, pp. 8347-8356, 2010.

[112] R. Buccione, G. Caldieri, and I. Ayala, "Invadopodia: specialized tumor cell structures for the focal degradation of 
the extracellular matrix," Cancer and Metastasis Reviews, vol. 28, no. 1-2, pp. 137-149, 2009.

[113] C. Albiges-Rizo, O. Destaing, B. Fourcade, E. Planus, and M. R. Block, "Actin machinery and mechanosensitivity in invadopodia, podosomes and focal adhesions," Journal of Cell Science, vol. 122, no. 17, pp. 3037-3049, 2009.

[114] U. Philippar, E. T. Roussos, M. Oser et al., "A Mena invasion isoform potentiates EGF-induced carcinoma cell invasion and metastasis," Developmental Cell, vol. 15, no. 6, pp. 813-828, 2008.

[115] D. A. Schafer, "Regulating actin dynamics at membranes: a focus on dynamin," Traffic, vol. 5, no. 7, pp. 463-469, 2004.

[116] G. Eitzen, "Actin remodeling to facilitate membrane fusion," Biochimica et Biophysica Acta, vol. 1641, no. 2-3, pp. 175-181, 2003.

[117] M. Egeblad and Z. Werb, "New functions for the matrix metalloproteinases in cancer progression," Nature Reviews Cancer, vol. 2, no. 3, pp. 161-174, 2002.

[118] M. Seiki, "Membrane-type 1 matrix metalloproteinase: a key enzyme for tumor invasion," Cancer Letters, vol. 194, no. 1, pp. 1-11, 2003.

[119] F. Saltel, T. Daubon, A. Juin, I. E. Ganuza, V. Veillat, and E. Génot, "Invadosomes: intriguing structures with promise," European Journal of Cell Biology, vol. 90, no. 2-3, pp. 100-107, 2011.

[120] M. A. Eckert and J. Yang, "Targeting invadopodia to block breast cancer metastasis," Oncotarget, vol. 2, no. 7, pp. 562-568, 2011.

[121] C. Badowski, G. Pawlak, A. Grichine et al., "Paxillin phosphorylation controls invadopodia/podosomes spatiotemporal organization," Molecular Biology of the Cell, vol. 19, no. 2, pp. 633-645, 2008.

[122] C. L. Cortesio, K. T. Chan, B. J. Perrin et al., "Calpain 2 and PTP1B function in a novel pathway with Src to regulate invadopodia dynamics and breast cancer cell invasion," The Journal of Cell Biology, vol. 180, no. 5, pp. 957-971, 2008.

[123] L. C. Kelley, A. G. Ammer, K. E. Hayes et al., "Oncogenic Src requires a wild-type counterpart to regulate invadopodia maturation," Journal of Cell Science, vol. 123, no. 22, pp. 3923-3932, 2010.

[124] L. Li, M. Okura, and A. Imamoto, "Focal adhesions require catalytic activity of Src family kinases to mediate integrinmatrix adhesion," Molecular and Cellular Biology, vol. 22, no. 4, pp. 1203-1217, 2002.

[125] S. Granot-Attas, C. Luxenburg, E. Finkelshtein, and A. Elson, "Protein tyrosine phosphatase epsilon regulates integrinmediated podosome stability in osteoclasts by activating Src," Molecular Biology of the Cell, vol. 20, no. 20, pp. 4324-4334, 2009.

[126] D. J. Webb, K. Donais, L. A. Whitmore et al., "FAK-Src signalling through paxillin, ERK and MLCK regulates adhesion disassembly," Nature Cell Biology, vol. 6, no. 2, pp. 154-161, 2004.

[127] H. Sasaki, K. Nagura, M. Ishino, H. Tobioka, K. Kotani, and T. Sasaki, "Cloning and characterization of cell adhesion kinase $\beta$, a novel protein- tyrosine kinase of the focal adhesion kinase subfamily," The Journal of Biological Chemistry, vol. 270, no. 36, pp. 21206-21219, 1995.

[128] R. Baron, "Molecular mechanisms of bone resorption: therapeutic implications," Revue du Rhumatisme (English Edition), vol. 63, no. 10, pp. 633-638, 1996.

[129] T. Miyazaki, A. Sanjay, L. Neff, S. Tanaka, W. C. Horne, and R. Baron, "Src kinase activity is essential for osteoclast function," The Journal of Biological Chemistry, vol. 279, no. 17, pp. 17660-17666, 2004.

[130] J. W. Triplett and F. M. Pavalko, "Disruption of $\alpha$-actininintegrin interactions at focal adhesions renders osteoblasts susceptible to apoptosis," American Journal of Physiology, vol. 291, no. 5, pp. C909-C921, 2006.

[131] S. A. Courtneidge, "Cell migration and invasion in human disease: the Tks adaptor proteins," Biochemical Society Transactions, vol. 40, no. 1, pp. 129-132, 2012.

[132] B. Blouw, D. F. Seals, I. Pass, B. Diaz, and S. A. Courtneidge, "A role for the podosome/invadopodia scaffold protein Tks5 in tumor growth in vivo," European Journal of Cell Biology, vol. 87, no. 8-9, pp. 555-567, 2008.

[133] I. Ayala, G. Giacchetti, G. Caldieri et al., "Faciogenital dysplasia protein Fgd1 regulates invadopodia biogenesis and extracellular matrix degradation and is up-regulated in prostate and breast cancer," Cancer Research, vol. 69, no. 3, pp. 747-752, 2009.

[134] G. W. McLean, N. O. Carragher, E. Avizienyte, J. Evans, V. G. Brunton, and M. C. Frame, "The role of focal-adhesion kinase in cancer-a new therapeutic opportunity," Nature Reviews Cancer, vol. 5, no. 7, pp. 505-515, 2005.

[135] V. G. Brunton and M. C. Frame, "Src and focal adhesion kinase as therapeutic targets in cancer," Current Opinion in Pharmacology, vol. 8, no. 4, pp. 427-432, 2008.

[136] H. Lahlou, V. Sanguin-Gendreau, D. Zuo et al., "Mammary epithelial-specific disruption of the focal adhesion kinase blocks mammary tumor progression," Proceedings of the National Academy of Sciences of the United States of America, vol. 104, no. 51, pp. 20302-20307, 2007.

[137] M. Luo, H. Fan, T. Nagy et al., "Mammary epithelial-specific ablation of the focal adhesion kinase suppresses mammary tumorigenesis by affecting mammary cancer stem/progenitor cells," Cancer Research, vol. 69, no. 2, pp. 466-474, 2009.

[138] B. Tavora, S. Batista, L. E. Reynolds et al., "Endothelial FAK is required for tumour angiogenesis," EMBO Molecular Medicine, vol. 2, no. 12, pp. 516-528, 2010.

[139] N. Koon, R. Schneider-Stock, M. Sarlomo-Rikala et al., "Molecular targets for tumour progression in gastrointestinal stromal tumours," Gut, vol. 53, no. 2, pp. 235-240, 2004.

[140] T. Miyazaki, H. Kato, M. Nakajima et al., "FAK overexpression is correlated with tumour invasiveness and lymph node metastasis in oesophageal squamous cell carcinoma," British Journal of Cancer, vol. 89, no. 1, pp. 140-145, 2003.

[141] C. R. Hauck, D. A. Hsia, X. S. Puente, D. A. Cheresh, and D. D. Schlaepfer, "FRNK blocks v-Src-stimulated invasion and experimental metastases without effects on cell motility or growth," The EMBO Journal, vol. 21, no. 23, pp. 6289-6302, 2002.

[142] C. R. Hauck, D. A. Hsia, D. Ilic, and D. D. Schlaepfer, "v-Src $\mathrm{SH} 3$-enhanced interaction with focal adhesion kinase at $\beta 1$ integrin-containing invadopodia promotes cell invasion," The Journal of Biological Chemistry, vol. 277, no. 15, pp. 12487-12490, 2002.

[143] C. Annerén, C. A. Cowan, and D. A. Melton, "The Src family of tyrosine kinases is important for embryonic stem cell self-renewal," The Journal of Biological Chemistry, vol. 279, no. 30, pp. 31590-31598, 2004.

[144] S. J. Parsons and J. T. Parsons, "Src family kinases, key regulators of signal transduction," Oncogene, vol. 23, no. 48, pp. 7906-7909, 2004.

[145] J. M. Su, L. Gui, Y. P. Zhou, and X. L. Zha, "Expression of focal adhesion kinase and $\alpha 5$ and $\beta 1$ integrins in 
carcinomas and its clinical significance," World Journal of Gastroenterology, vol. 8, no. 4, pp. 613-618, 2002.

[146] I. Tanjoni, C. Walsh, S. Uryu et al., "PND-1186 FAK inhibitor selectively promotes tumor cell apoptosis in threedimensional environments," Cancer Biology and Therapy, vol. 9, no. 10, pp. 764-777, 2010.

[147] S. Roelle, R. Grosse, T. Buech, V. Chubanov, and T. Gudermann, "Essential role of Pyk2 and Src kinase activation in neuropeptide-induced proliferation of small cell lung cancer cells," Oncogene, vol. 27, no. 12, pp. 1737-1748, 2008.

[148] S. Zhang, X. Qiu, Y. Gu, and E. Wang, "Up-regulation of proline-rich tyrosine kinase 2 in non-small cell lung cancer," Lung Cancer, vol. 62, no. 3, pp. 295-301, 2008.

[149] M. J. van Nimwegen, S. Verkoeijen, L. van Buren, D. Burg, and B. van de Water, "Requirement for focal adhesion kinase in the early phase of mammary adenocarcinoma lung metastasis formation," Cancer Research, vol. 65, no. 11, pp. 4698-4706, 2005.

[150] L. Tremblay, W. Hauck, A. G. Aprikian, L. R. Begin, A. Chapdelaine, and S. Chevalier, "Focal adhesion kinase (pp125FAK) expression, activation and association with paxillin and p50CSK in human metastatic prostate carcinoma," International Journal of Cancer, vol. 68, no. 2, pp. 164-171, 1996.

[151] H. Sun, S. Pisle, E. R. Gardner, and W. D. Figg, "Bioluminescent imaging study: FAK inhibitor, PF-562,271, preclinical study in PC3M-luc-C6 local implant and metastasis xenograft models," Cancer Biology and Therapy, vol. 10, no. 1, pp. 38-43, 2010.

[152] P. P. Eleniste, L. Du, M. Shivanna, and A. Bruzzaniti, "Dynamin and PTP-PEST cooperatively regulate Pyk2 dephosphorylation in osteoclasts," The International Journal of Biochemistry \& Cell Biology, vol. 44, no. 5, pp. 790-800, 2012.

[153] B. Desai, T. Ma, and M. A. Chellaiah, "Invadopodia and matrix degradation, a new property of prostate cancer cells during migration and invasion," The Journal of Biological Chemistry, vol. 283, no. 20, pp. 13856-13866, 2008.

[154] A. Gutenberg, W. Brück, M. Buchfelder, and H. C. Ludwig, "Expression of tyrosine kinases FAK and Pyk2 in 331 human astrocytomas," Acta Neuropathologica, vol. 108, no. 3, pp. 224-230, 2004.

[155] Z. Li, X. Yuan, Z. Wu, Z. Guo, P. Jiang, and Z. Wen, "Expressions of FAK and Pyk2 in human astrocytic tumors and their relationship with angiogenesis," Chinese-German Journal of Clinical Oncology, vol. 7, no. 11, pp. 658-660, 2008.

[156] T. P. Hecker, J. R. Grammer, G. Y. Gillespie, J. Stewart Jr., and C. L. Gladson, "Focal adhesion kinase enhances signaling through the Shc/extracellular signal-regulated kinase pathway in anaplastic astrocytoma tumor biopsy samples," Cancer Research, vol. 62, no. 9, pp. 2699-2707, 2002.

[157] Q. Shi, A. B. Hjelmeland, S. T. Keir et al., "A novel lowmolecular weight inhibitor of focal adhesion kinase, TAE226, inhibits glioma growth," Molecular Carcinogenesis, vol. 46, no. 6, pp. 488-496, 2007.

[158] A. H. Sikkema, S. H. Diks, W. F. A. den Dunnen et al., "Kinome profiling in pediatric brain tumors as a new approach for target discovery," Cancer Research, vol. 69, no. 14, pp. 5987-5995, 2009.

[159] S. M. Weis, S. T. Lim, K. M. Lutu-Fuga et al., "Compensatory role for Pyk2 during angiogenesis in adult mice lacking endothelial cell FAK," The Journal of Cell Biology, vol. 181, no. 1, pp. 43-50, 2008.
[160] Y. Duan, J. Learoyd, A. Y. Meliton, B. S. Clay, A. R. Leff, and $\mathrm{X}$. Zhu, "Inhibition of Pyk2 blocks airway inflammation and hyperresponsiveness in a mouse model of asthma," American Journal of Respiratory Cell and Molecular Biology, vol. 42, no. 4, pp. 491-497, 2010.

[161] Y. Yu, S. A. Ross, A. E. Halseth et al., "Role of PYK2 in the development of obesity and insulin resistance," Biochemical and Biophysical Research Communications, vol. 334, no. 4, pp. 1085-1091, 2005.

[162] M. Okigaki, C. Davis, M. Falascat et al., "Pyk2 regulates multiple signaling events crucial for macrophage morphology and migration," Proceedings of the National Academy of Sciences of the United States of America, vol. 100, no. 19, pp. 10740-10745, 2003.

[163] D. Lang, A. V. Glukhov, T. Efimova, and I. R. Efimov, "Role of Pyk2 in cardiac arrhythmogenesis," American Journal of Physiology Heart and Circulatory Physiology, vol. 301, no. 3, pp. H975-H983, 2011.

[164] G. M. Fabrizi, M. Ferrarini, T. Cavallaro et al., "Two novel mutations in dynamin-2 cause axonal Charcot-Marie-Tooth disease," Neurology, vol. 69, no. 3, pp. 291-295, 2007.

[165] J. Böhm, V. Biancalana, E. T. Dechene et al., "Mutation spectrum in the large GTPase dynamin 2, and genotypephenotype correlation in autosomal dominant centronuclear myopathy," Human Mutation, vol. 33, no. 6, pp. 949-959, 2012.

[166] P. N. M. Sidiropoulos, M. Miehe, T. Bock et al., "Dynamin 2 mutations in Charcot-Marie-Tooth neuropathy highlight the importance of clathrin-mediated endocytosis in myelination,” Brain, vol. 135, no. 5, pp. 1395-1411, 2012. 

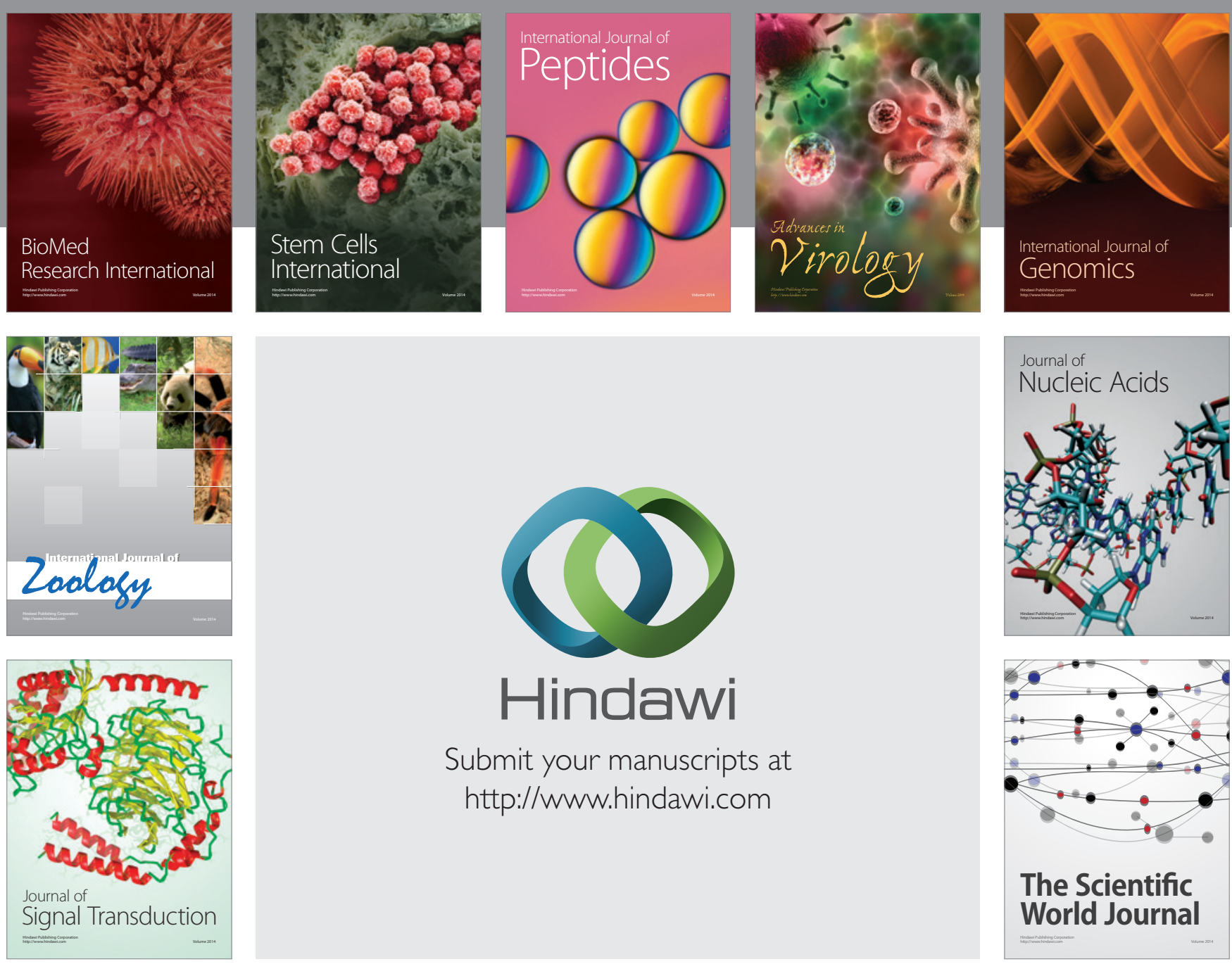

Submit your manuscripts at

http://www.hindawi.com
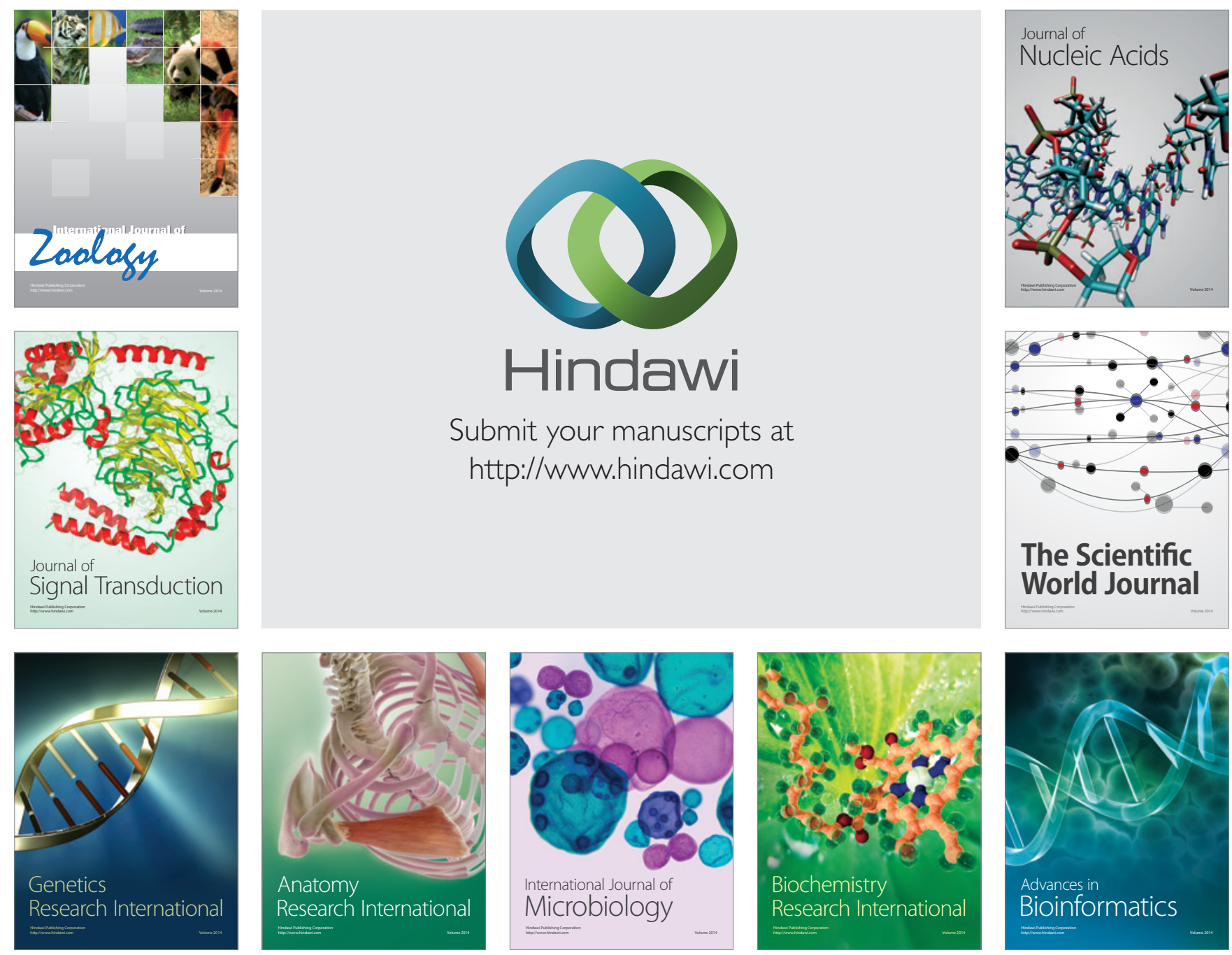

The Scientific World Journal
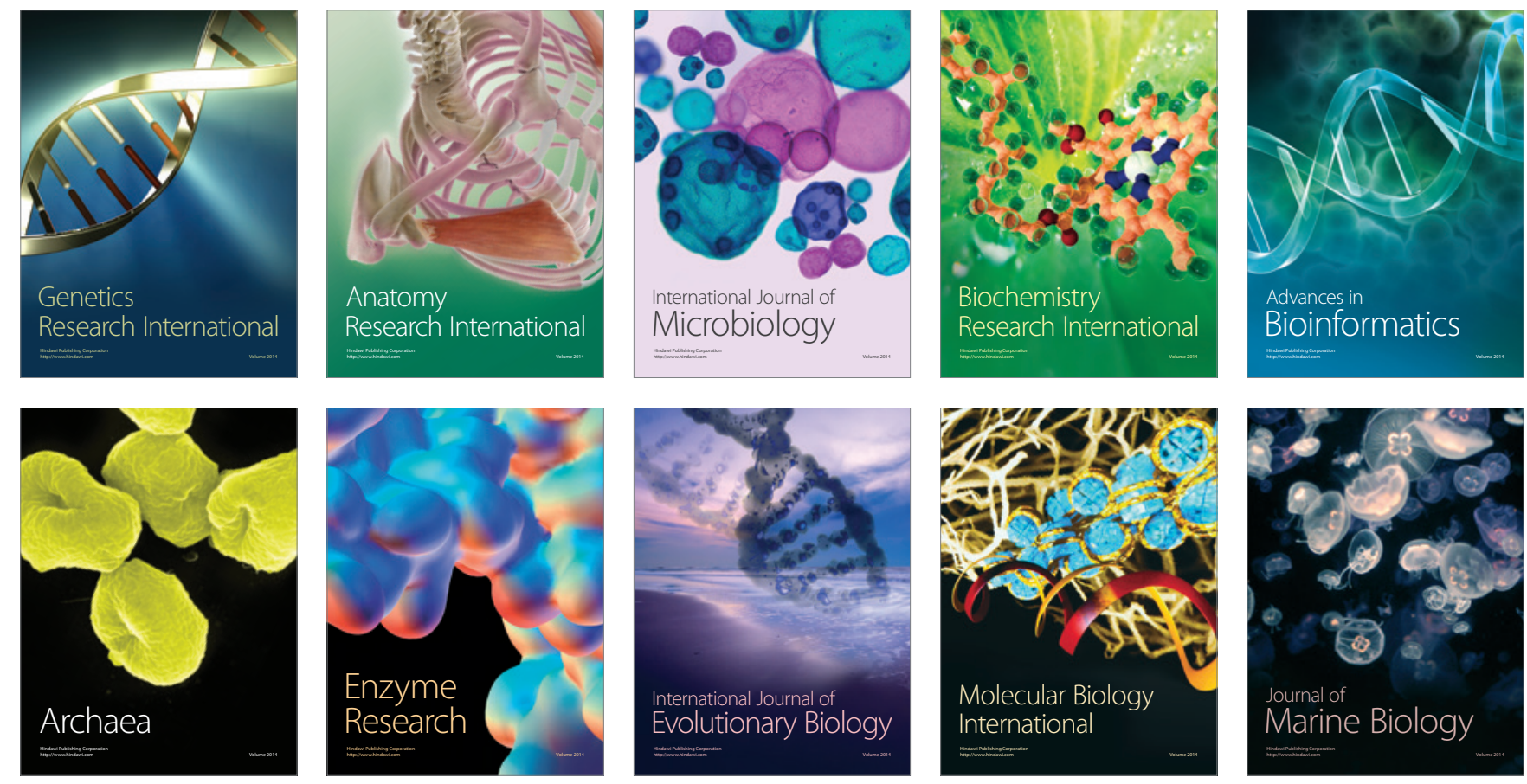